\title{
A Study of pattern of neck injuries in the victims autopsied at tertiary care medical college and hospital of North Karnataka
}

\author{
Faisal Nasim Gilani ${ }^{1}$, Ashokkumar Rajaput ${ }^{2 *}$, E.S.Goudar ${ }^{3}$ \\ ${ }^{1,2}$ Assistant Professor, ${ }^{3}$ Professor and Head, ${ }^{1-3}$ Dept. of Forensic Medicine and Toxicology, ${ }^{\mathbf{1}}$ GS Medical College and Hospital, Pilkhuwa, \\ Hapur, Uttar Pradesh, ${ }^{2}$ Ashwini Rural Medical College, Solapur, Maharashtra, ${ }^{3}$ Al-Ameen Medical College and Hospital, vijayapura, \\ Karnataka, India
}

\section{*Corresponding Author: Ashokkumar Rajaput}

Email: drfaisalgilani@gmail.com

\begin{abstract}
Introduction: Death due to neck injuries are invariably encountered in medicolegal work. Injuries to neck causing death can occur in different manner and different circumstances.

Objectives: To know about the neck wounds, neck structures (organs) commonly involved, agents, manner and cause of death due to neck injuries.

Material and Methods: 208 victims of neck injuries were autopsied at Al-Ameen Medical College Mortuary and District Hospital Mortuary, Bijapur (Karnataka) from June 2011 to May 2014. It was a one year retrospective and two years prospective study.

Results: Out of 208 victims of neck injuries autopsied, most vulnerable age group was 21-30 yrs (30.76\%) followed by age group 31-40yrs $(27.88 \%)$. Cervical vertebrae fracture and dislocation was the most common skeletal injury in neck region (18.26\%). It was found that Suicide by hanging $(40.38 \%)$ was the most common manner of death followed by road traffic accidents $(31.73 \%)$. Major cause of death was mechanical asphyxia (53.84\%).

Conclusion: Neck injuries constitute a potential factor in increasing the amount of mortality and morbidity. The conclusions evolved from the present study may be useful in medicolegal work and if possible to make suggestions for prevention and safety measures.
\end{abstract}

Keywords: Manner, Agents and Cause of death, Neck organs involved.

\section{Introduction}

Trauma is one of the leading preventable causes of death in developing countries and is posing major health and social problem. Death related trauma rank third after cardiovascular diseases and cancer. Trauma may lead to short or long term disability. Since neck contains the vital organs like thyroid gland, parathyroid glands, thymus, larynx, trachea, esophagus etc, great vessels and supporting tissue, trauma to this region challenges the integrity and even the viability of the individual. ${ }^{1}$ The size and anatomical position of the neck makes it a major site of trauma in suicide, homicide, road accidents, machinery accidents and fall from height etc. Neck trauma causes $10-15 \%$ of all mortalities. In case of neck, trauma can produce a wide spectrum of injuries extending from the fracture of bones like hyoid bone, thyroid cartilage, vertebrae etc and injuries of neck structures like contusions, lacerations, abrasions etc. $^{2}$

It is learnt from literature that neck injuries are encountered with different manner (suicide, homicide, accident). Sometimes homicidal neck injuries are pleaded or disguised as suicide e.g. murdered victims placed on railway track and even accidental neck injuries are disguised as homicidal to bring false charge of offence on enemies. Meticulous examination of neck injuries can give clues to settle these challenges (Suicidal, homicidal or accidental). Over all, suicide is the major cause of neck injury because of social, economic, work pressure, love failure; failure in exams, unemployment, marital disharmony and depression etc. Accidental deaths are an unplanned event occurring suddenly unexpectedly as unforeseen circumstance. The exponentially increasing number of automobile vehicles, poor adherence to traffic rules and regulations, abuse of alcohol and drug are the cause of accidents. Accidents tragically are not often due to ignorance, but are also due to carelessness, thoughtlessness and due to over confidence. Incidence of road traffic accidents has been increasing at the alarming rate throughout the world. Due to narrow roads and excess motor vehicles, road traffic accidents result leading to blunt neck trauma. Neck injuries are one of the major causes of death despite optimal use of available treatment facilities.

Homicides are also on rise because of increasing population, unemployment, industrialization, easy availability of the weapons and stressful living conditions. Besides that, there are many natural household objects like lathi, kitchen knife, screwdriver, razor blade, broken bottles, stone, axe and scissors. The incidence of neck trauma has increasing significantly due to development of rapid means of transport and rising the level of violence in the society in general. About 100 to130 cases of homicides takes place every day in India. The Studies specific to neck injuries are not being done in this region. In view of this, the present study is undertaken. The conclusions evolved from present study may be useful in similar medicolegal work and if possible, to make suggestions for prevention and safety measures.

\section{Materials and Methods}

The present study was done for one-year retrospective and two years prospective study from June2011 to May 2014 at Al-Ameen medical college mortuary and District hospital mortuary, Bijapur. (Karnataka) 
All the cases autopsied were screened for neck injuries resulting from deaths due to road traffic accidents, machinery accidents, assault, firearm injuries, fall from height and suicide etc. A detailed information and data pertaining to the cases were collected. After receiving the details, post-mortem examination was conducted and cause of death was determined.

Information pertaining to agent and manner of death was sought from the police personnel investigating the case. Some of the particulars of the victim were also obtained from the direct interrogation with relatives, friends and others along with the police. Following points were noted with respect to age, sex, manner of death, agents causing the injury, frequency of organs involved, relationship with fall from height and the cause of death.

All the findings thus obtained were noted down in a separate performa for each case. Then the master chart was prepared. The statistical analysis of the data collection was done and presented in the form of tables. Photographs were taken whereever necessary.

\section{Inclusion Criteria}

All the victims of neck injuries autopsied at Al-Ameen Medical College mortuary and District hospital mortuary, Bijapur. (Karnataka)

\section{Exclusion Criteria}

All the victims autopsied at Al-Ameen Medical College mortuary and District hospital mortuary, Bijapur other than victims of neck injury.

\section{Results and Discussion}

The present study was done for one-year retrospective and two years prospective study from June 2011 to May 2014 in Al-Ameen medical college and District hospital Mortuary, Bijapur. (Karnataka). During this period, 1504 cases were brought for postmortem examination. 208 autopsied cases were of neck injuries but 146(70.19\%) victims died due to neck injury proper and $62(29.80 \%)$ victims died due to associated injuries with non-fatal neck injuries. Out of 208 autopsied cases, 166 were males and 42 were females. The male and female ratio was $\mathrm{M}: \mathrm{F}=3.95: 1$. The mean average age was 33.88 years.

In our study, out of 208 autopsied cases of neck injuries, 146 victims died due to neck injuries proper and 62 (29.80\%) victims died due to associated injuries with nonfatal neck injuries. Our present study result was compared and discussed with other studies as follows: - Almost similar finding i.e.10.50\% of total number of autopsied cases was documented by Ajay Kumar S et al. ${ }^{3}$ Patel Ankur $\mathrm{P}$ et $\mathrm{al}^{4}$ in their study revealed incidence of asphyxial death to be $5.63 \%$ of total autopsies (6880 cases) which was inconsistent with our findings. The reason may be due to total number of autopsies were more in their study.

The present study reveals most vulnerable age group is $21-30$ years $(n=64,30.76 \%)$ followed by $31-40$ years $(n=58$, $27.88 \%)$ and minimum death in the age group of 0-10years $(\mathrm{n}=10,4.80 \%)$ and $>60$ years $(\mathrm{n}=10,4.80 \%)$. The average mean age was $33.88 \mathrm{yrs}$.

These findings were in agreement with studies done by Sharma BR et al ${ }^{5}$, Ajay Kumar S et $\mathrm{al}^{3}$, Patel Ankur P et al ${ }^{4}$.

In comparison with study done by Dharmaraya Ingale et $\mathrm{al}^{6}$, their finding agrees as far as vulnerable age was concerned (21-30 yrs). In their study, next vulnerable age group was 11-20 yrs., which was in contrast with our results wherein next vulnerable age group in our study was 3140yrs.

Age group of 21-40yrs was the most functional group of any population. They are primary bread earners of the family, more active, have tendency to take more undue risks, thereby subjecting themselves to the hazards of accidents and injuries. The minimum cases were seen in children and late years. Children are taken care of the elders and those aged 60yrs and above could be due to generally less mobility of these population groups.

Table 1: Showing percentage of neck injury victims out of 1504 autopsied cases

\begin{tabular}{|c|l|c|}
\hline Total number of autopsies & No. of neck injury cases & Percentage \\
\hline 1504 & 208 & $13.82 \%$ \\
\hline
\end{tabular}

Table 2: Showing percentage of death due to neck injury proper:

\begin{tabular}{|l|c|c|}
\hline \multicolumn{1}{|c|}{ Death } & Total & Percentage \\
\hline Death due to neck injuries proper & 146 & $70.19 \%$ \\
\hline Death due to associated injuries with non-fatal neck injuries. & 62 & $29.80 \%$ \\
\hline
\end{tabular}

Table 3: Age- wise distribution of the victims

\begin{tabular}{|c|c|c|c|c|}
\hline \multirow{2}{*}{ Age group (years) } & \multicolumn{2}{|c|}{ No. of Victims } & \multirow{2}{*}{ Total } & \multirow{2}{*}{ Percent } \\
\cline { 2 - 3 } & Male & Female & & 4.80 \\
\hline $0-10$ & 06 & 04 & 24 & 11.53 \\
\hline $10-20$ & 12 & 12 & 64 & 30.76 \\
\hline $20-30$ & 52 & 12 & 58 & 27.88 \\
\hline $30-40$ & 50 & 08 & 18 & 08.65 \\
\hline $40-50$ & 18 & 00 & 24 & 11.53 \\
\hline $50-60$ & 18 & 06 & 10 & 04.80 \\
\hline$>60$ & 10 & 00 & 208 & 100 \\
\hline Total & 166 & 42 & \\
\hline
\end{tabular}


Table 4: Sex- wise distribution of the victims

\begin{tabular}{|c|c|c|}
\hline Sex & No. of victims & Percentage \\
\hline Male & 166 & 79.80 \\
\hline Female & 42 & 20.19 \\
\hline Total & 208 & 100 \\
\hline
\end{tabular}

Table 5: Agents causing injuries

\begin{tabular}{|l|l|l|c|c|}
\hline \multicolumn{1}{|c|}{ Agents } & \multicolumn{1}{|c|}{ Types of agents } & No of cases & Percentage \\
\hline 1.Constriction force $(\mathrm{n}=88)$ & Ligature material & 1. Saree & 14 & 15.90 \\
& & 2. Nylon rope & 08 & 09.09 \\
& & 3. Rope & 26 & 29.54 \\
& & 4. Dupatta & 10 & 11.36 \\
& & 5. Dhoti & 08 & 09.09 \\
& & 6. Telephone cable & 02 & 02.27 \\
& & 7. Lungie & 08 & 09.09 \\
& & 8. Cotton rope & 06 & 06.81 \\
& & 9. Electric wire & 06 & 06.81 \\
\hline 2.Compression force $(\mathrm{n}=24)$ & 1.Manual strangulation & 04 & 16.66 \\
& 2.Ligature strangulation & 20 & 83.33 \\
\hline 3.Blunt force (n=66) & 1.RTA & 60 & 90.90 \\
& 2.Fall from height & 06 & 09.09 \\
\hline 4.Penetrating force(n=24) & 1.Sharp weapon & 08 & 33.33 \\
& 2.Fire arm & 02 & 08.33 \\
& 3.Heavy sharp cutting weapon & 14 & 58.33 \\
\hline 5. Explosion\& roof fall $(\mathrm{n}=02)$ & 02 & 100 \\
\hline 6.Machinery agents $(\mathrm{n}=04)$ & 1.Machine belt & 02 & 50.00 \\
& 2.Cutting machine & 02 & 50.00 \\
\hline
\end{tabular}

Table 6: Types of neck organs involved:

\begin{tabular}{|l|c|c|}
\hline \multicolumn{1}{|c|}{ Neck organs involved } & No. of cases & Percentage \\
\hline Sternocleidomastoid & 18 & 08.65 \\
\hline Strap Muscles & 22 & 10.57 \\
\hline Hyoid Bone & 16 & 07.69 \\
\hline Thyroid Cartilage & 14 & 06.73 \\
\hline Cricoid Cartilage & 14 & 06.73 \\
\hline Neck vessels & 24 & 11.53 \\
\hline Larynx/Trachea(LT) (including 4Tracheostomy cases) & 28 & 13.46 \\
\hline Mouth, pharynx, esophagus (MPO) & 18 & 08.65 \\
\hline LT + MPO & 38 & 18.26 \\
\hline Cervical vertebrae & 42 & 20.19 \\
\hline
\end{tabular}

Table 7: Relationship with fall from height

\begin{tabular}{|c|c|c|}
\hline Height in feet & No. of cases & Percentage \\
\hline$<10 \mathrm{ft}$ & 00 & 00.00 \\
\hline $11-20 \mathrm{ft}$ & $02($ Male $)$ & 33.33 \\
\hline $20-30 \mathrm{ft}$ & $02($ Male $)$ & 33.33 \\
\hline $30-40 \mathrm{ft}$ & $02($ Male $)$ & 33.33 \\
\hline Total & 06 & 100 \\
\hline
\end{tabular}

Table 8: Manner of death

\begin{tabular}{|l|c|c|c|c|}
\hline \multicolumn{1}{|c|}{ Circumstances } & \multicolumn{2}{c|}{ No. of Victims } & \multirow{2}{*}{ Total } & \multirow{2}{*}{ Percent } \\
\cline { 2 - 3 } & Male & Female & & \\
\hline 1.Accidental & & & & \\
a. RTA death & 60 & 06 & 66 & 31.73 \\
b. Fall from height death & 06 & 00 & 06 & 02.88 \\
c. Machinery accidental death & 06 & 00 & 06 & 02.88 \\
\hline Homicidal & 30 & 16 & 46 & 22.11 \\
\hline Suicidal & 64 & 20 & 84 & 40.38 \\
\hline \multicolumn{1}{|c|}{ Total } & 166 & 42 & 208 & 100 \\
\hline
\end{tabular}


Table 9: Cause of death

\begin{tabular}{|l|c|c|c|c|}
\hline \multicolumn{1}{|c|}{ Total no of asphyxia death $(\mathbf{n = 1 1 2 , 5 3 . 8 4 \% )}$} & Male & \% & emale & \% \\
\hline Hanging $(\mathrm{n}=88,78.57 \%)$ & 68 & 60.71 & 20 & 7.85 \\
\hline Ligature strangulation $(\mathrm{n}=20,17.85 \%)$ & 14 & 12.50 & 06 & 5.35 \\
\hline Manual strangulation $(\mathrm{n}=4,3.57 \%)$ & 00 & 00 & 04 & 3.57 \\
\hline Hemorrhagic shock $(\mathbf{n}=\mathbf{4 2 , 2 0 . 1 9 \% )}$ & 30 & 71.42 & 12 & 8.57 \\
\hline Coma $(\mathbf{n}=\mathbf{5 0 , 2 4 . 0 3 \% )}$ & 50 & 100 & 00 & 00.00 \\
\hline Decapitation $(\mathbf{n}=\mathbf{4 , 1 . 9 2 \% )}$ & 04 & 100 & 00 & 00.00 \\
\hline
\end{tabular}

In the present study, males $(\mathrm{n}=166,79.80 \%)$ outnumbered females $(n=42,20.19 \%)$. The male and female ratio was M: $\mathrm{F}=3.95: 1$. Our results were consistent with results of Jayaprakash $\mathrm{S}$ et $\mathrm{al}^{3}$ i.e. male percentage being $70.9 \%$.but was in contrast with the study conducted by Zahid Husain et $\mathrm{al}^{7}{ }^{7}$ and Patel Ankur $\mathrm{P}$ et al ${ }^{4}$ the $\mathrm{M}: \mathrm{F}$ ratio is 5.5:1 and 1.69:1 respectively,. Our results also did not agree with respect to male and female $\%$ involved in the study conducted by Dharmaraya Ingale et $\mathrm{al}^{6}$ i.e. $\mathrm{M}=58.39 \%$ and $\mathrm{F}=41.60 \%$.

Our results and others study finding suggested males outnumbered females. This was because males are more exposed to hazards of roads, industry, machinery, violence, as they constitute working and earning member in majority of the families while females usually stay at home and look after the children and household works. Other factors might be Unemployment, love disappointment, marital disharmony, financial problems, revenge etc. Moreover, males are more aggressive than females.

For constriction force, ligature material used was saree in 14 cases, nylon rope in 8 cases, dupatta in 10 cases, dhoti in 08 cases, telephone cable in 02 case, Lungie in 8 cases, cotton rope in 6 cases, electric wire in 6 cases and rope in 26 cases. For compression force, hands were used in 4 cases (manual strangulation) whereas ligature material was used in 20 cases (ligature strangulation).For blunt Force, 60 different vehicular agents were involved whereas in 6 cases of fall from height, hard rough surfaces were involved. For Penetrating Force, 8 sharp weapons were used, 2 cases were of Gun Shot and in 14 cases heavy sharp cutting weapon were used. 2cases of explosion with roof fall were seen. 04 cases of machinery agents were encountered.

In the present study, it was found that agents responsible for majority of neck injuries is the constricting force that is Ligature material in 88 out of 208 cases $(42.30 \%)$. Amongst ligature material, rope was used in most of the cases i.e. $26(29.54 \%)$ and saree was used in 14 cases $(15.90 \%)$.

Dharmaraya Ingale et al ${ }^{6}$ found in their study that rope was used in $25.40 \%$ of neck injury victims followed by Saree, which was $21.84 \%$.This study, is comparable to our study.

BR Sharma et $\mathrm{al}^{8}$ has documented that chunni was used in $31 \%$ of victims of neck injuries followed by nylon rope in $18 \%$ victims. Their observations are contrast to our results.

Sadikhusen G. Momin et $\mathrm{al}^{9}$ states that chunni was also used in $34.44 \%$ victims in their study followed by nylon rope which was $31.1 \%$. Their results are in contrast to our finding.
In the present study, we noticed slit in the neck (cutthroat injury) and associated injury was there on the chest. Zahid Husain et $\mathrm{al}^{7}$ finding are almost similar to our results. However, their study comprised of 452 victims. In the present study, only 2 cases of firearm were seen. Our study differs as regards to site of firearm injury. The most common firearm weapons used in their study were Kalashnikov, rifles, pistols followed by rifled weapons and shotguns. Whereas in our study, country made weapon was used.

In our study, machinery accidents were seen in 4 cases and cylinder explosion and roof fall cases were also two.. In all the 6 cases, victims were Male. It constitutes $2.88 \%$ of the total cases.In Machinery accidents, agents were Machine belt and second as harvesting machine.

In the present study it was observed that Cervical vertebrae (Fracture and Dislocation) was the most common organ injured in the majority of the victims i.e., 42cases (20.19\%), followed by (Larynx and Trachea plus Mouth, Pharynx, Esophagus) in 38 cases $(18.26 \%)$ which was followed by larynx and trachea in 28 cases $(13.46 \%)$. In our study, injury of great neck vessels were seen in 24 cases $(11.53 \%)$. Strap muscles in 22 cases $(10.57 \%)$. Mouth, pharynx and esophagus were injured in 18 cases $(8.65 \%)$. Sternocleidomastoid muscles were injured in 18 cases (8.65\%). Hyoid bone (fracture and cut injury) in 19 cases (7.69\%), thyroid and Cricoid cartilage were injured in 14 cases each $(6.73 \%)$.

A Cervical vertebra $(\mathrm{Cv})$ (fracture and dislocation) was the most common organ injured in our study in majority of the victims. Exact number of victims at various levels were-a) Atlantoccipital joint- 16 victims b) $2 \mathrm{nd} \& 3^{\text {rd }} \mathrm{Cv}-8$ victims c) $3^{\text {rd }} \& 4^{\text {th }}-4$ victims d) $4^{\text {th }} \& 5^{\text {th }} \quad C v-2$ victims e) $5^{\text {th }} \& 6^{\text {th }} \mathrm{Cv}--4$ victims f) $\left.6^{\text {th }} \& 7^{\text {th }} \mathrm{Cv}-02 \mathrm{~g}\right) 7^{\text {th }} \mathrm{CV}-2$ victims h)All over-4victims.. Total are 42 victims at various cervical vertebrae level. Our results are in contrast with the study done by Jayaprakash $\mathrm{S}$ et $\mathrm{al}^{10}$ in which he finds only $1.6 \%$ of vertebral fracture and dislocation. Rupture of Sternocleidomastoid muscle is found to be $19.6 \%$ in his study whereas it is only $8.65 \%$ in our study. Sharma BR et $\mathrm{al}^{5}$ noted in their study that commonest neck injury were injury to the Sternocleidomastoid muscle (54\%) followed by hyoid bone fracture $(21 \%)$ and thyroid cartilage fracture (17\%) which is in contrast to our study. Our results involving cervical vertebrae are almost consistent with the reports and studies of Daniel J Sptiz et al, ${ }^{11}$ Sanjay Gupta, ${ }^{12}$ Bahadur Kumral et al, ${ }^{13}$ AH Meshram et al, ${ }^{14}$ Eloisa Maselli et al. ${ }^{15}$ 
Out of 208 cases, autopsied only 6 cases of fall were encountered. Two male victims aged 14 years and 16 years fell from top of the bus with height of approx 14 feet. Two male-aged 42 years and 46 years fell from top of the overloaded lorry with height of approx 20 feet. Two maleaged 24 years and 22 years fell from under construction house with height of 35 feet. In the present study, coma was the cause of death. Victim's age ranges from 14-46 years. All victims were Male. The neck injuries due to fall from height were less than 10 feet is seen in 0 cases followed by fall from height of 11-20 feet in 2cases, 20-30 feet in 02 cases and 30-40 feet in 02 cases. Manner of deaths in fall from height was due to accidental fall. It accounted for total 6 cases $(2.88 \%)$ out of 208 cases of neck injuries. Our finding was almost near to the studies of Ling li et $\mathrm{al}^{16}$ where they documented more than 50\% victims fell accidently and majority victims were male between 20$40 \mathrm{yrs}$ which is consistent with our study. Our results are in accordance with the studies of C.R.Vasudeva Murthy et $\mathrm{al}^{17}$ where they have mentioned that most cases of fall from height were accidental in nature, younger males were the major victims, and most of the deaths in victims occurred between $0-40$ feet height. Turk EE et $\mathrm{al}^{18}$ noticed in their study that deaths due to fall from height were more common in males and severe head injuries predominantly occurred which were similar to our study but most cases of fall from height were suicidal in nature is in non agreement with our study.

In our study it was found that males accounts for 64 , females accounting for 20 and the total being 84 in suicidal circumstances $(40.38 \%)$. In accidental circumstances, it is noticed that 72 males and 06 females and total being 78 (37.50\%) which includes RTA death being 66(31.73\%), fall from height death victim were $6(02.88 \%)$ and machinery accidents (including explosive) victims being $6(02.88 \%)$. In homicidal circumstances, males accounting for 30 and females accounting for 16 and total being 46(22.11\%). The manner of death in present study is maximum suicidal in nature followed by accidental and homicidal. In all manner of death, male predominance was noticed. In our study the manner of death is maximum in suicidal circumstances i.e. $84(40.38 \%)$ followed by accidental circumstances i.e. $78(37.5 \%)$ and homicidal deaths i.e. $46(22.11 \%)$.Out of 78 cases of accidental fatalities, commonest cause of injury was the road traffic accident. Out of $84(40.38 \%)$ suicidal fatalities, commonest cause of injury was asphyxial death.(Hanging)

Our study was in agreement with the studies of Patel Ankur $\mathrm{P}$ et $\mathrm{al}^{4}$ as they mention in their study that suicidal hanging (neck injury) were most common (97.5\%) followed by accidental and homicidal. Our study was also consistent with the studies of Ajay Kumar S et $\mathrm{al}^{3}$, Shetty BS et al, ${ }^{19}$ Aleksandra Apostolov et al, ${ }^{20}$ Sikary AK et al, ${ }^{21}$ Smith Srisont. ${ }^{22}$ Our findings were in contrast with the studies of Zahid Hussein et $\mathrm{al}^{7}$ as they have noticed homicidal deaths constituted maximum numbers $(77.7 \%)$ of all autopsies conducted in their study.
In our study, total number of mechanical asphyxia death was 112 out of 208.68 males $(60.71 \%)$ and 20 females (17.85) died due to hanging followed by 14 males $(12.50 \%)$ and 6 females $(5.35 \%)$ due to ligature strangulation followed by only 4 females $(3.57 \%)$ who died due to manual strangulation. In our study, 42 out of 208 victims died due to hemorrhagic shock of which males $30(71.42 \%)$ and females $12(28.57 \%)$ Coma as cause of death noticed in the present study in 50 male victims (100\%) out of 208...Decapitation as a cause of death was noticed in 4 males out of 208 cases. Our results of hanging were consistent with Dharmaraya Ingale et $\mathrm{al}^{6}$ findings as far as Male victims are concerned i.e.58.39 percentage whereas his findings was in contrast as far as female victims are concerned i.e. $41.60 \%$ which was more.

Our results were in agreement with Ajay Kumar $\mathrm{S}$ et $\mathrm{al}^{3}$ where he reported hanging was the most common type of asphyxial death accounting for $80.60 \%$. Our results were not comparable with his study as regards to ligature strangulation (4 cases, 5.5\%). Our observations were similar to the observation made by Patel Ankur et $\mathrm{al}^{4}$; males were commonly affected in their study. They state hanging (82.48\%) was the most common cause of death followed by strangulation $(3.09 \%)$. Our results of asphyxia deaths were in agreement with study done by Sharma BR et $\mathrm{al}^{5}$ who found hanging $(69 \%)$ outnumbered other asphyxial deaths like ligature and Manual strangulation. In our study, hemorrhagic shock was also one of the leading causes of death, which is similar to study of other authors like Zahid Hussain et al, ${ }^{7}$ Shetty BS et al, ${ }^{19}$ Parthasarathi Pramanik et $\mathrm{al}^{23}$, Smith Srisont et $\mathrm{al}^{22,}$ Aleksandar Apostolov et $\mathrm{al}^{20}$. In our study, minimum number of cause of death was due to decapitation i.e. 4 cases $(1.92 \%)$ out of 208 cases of neck injuries which was almost nearer to the finding of Bahadur Kumral et al ${ }^{13}$.

In our study, we have not encountered suicide by ligature strangulation due to precipitating or predisposing cause for committing suicide whereas in contrast to our study, Serafettin Demirci et al ${ }^{24}$ in their study they found 3 cases of suicide by ligature strangulation with preexisting factors like Depression, Bronchial Asthma and Schizophrenia. In the present study, we have not encountered a person committing suicide by stabbing and cutting him where injury was seen in the neck, the precipitating factor was AIDS (acquired immuno deficiency syndrome) in contrast to Smith Srisont et $\mathrm{al}^{22}$ who states that a male with 27 yrs old committed suicide by stabbing and cutting himself with few injuries on the neck. The precipitating cause was AIDS.(acquired immunodeficiency syndrome). In the present study, we encountered tracheotomy as a neck injury in 08 cases. After reviewing available literature, no investigator found or cites in their studies. Our results were in contrast with other studies. We had not encountered seat belt injuries even some people possess. 


\section{Conclusion}

Neck injuries constitute a potential factor in increasing the amount of morbidity and mortality; therefore proper attention should be paid towards their accurate diagnosis and satisfactory management. Death in young due to neck injuries causes heavy loss of valuable work force and human resources. In the present study, it was found that suicide was the most common manner of death followed by road traffic accident. To prevent suicidal deaths, help lines taken care of by team of psychologists, social workers, counselors and nurses should assist people in stress and at risk to commit suicides. To combat road traffic accidents, traffic rules should be obeyed and trained emergency team with well equipped advance ambulance should be available on time etc.

\section{Conflict of Interest: None.}

\section{References}

1. Chaurasia's BD. Human Anatomy Head, Neck and Brain. Regional and Applied section and Clinical, Fourth Edition, CBS Publishers and Distributors, New Delhi; 2004:38-240.

2. Dr K S Narayan Reddy, $30^{\text {th }}$ Edition, Published by K.Suguna Devi, Hyderabad Page No: 241.

3. Ajay Kumar S, Chandan V, Y. C. Rudresh, H.C.Govindaraju, Sidramappa Gouda. Study of Violent Asphyxia Deaths in Chitradurga district of Karnataka. Int J Biomed Advance Res 2013;04(12):868-71

4. Patel-Ankur P, Bhoot-Rajesh R, Patel-Dhaval J, Patel Khushbu A. Study of Violent Asphyxial Death. Int J Med Toxicol Forensic Med 2013; 3(2):48-57.

5. Sharma BR, Harish D, Sharma A, Sharma S, Singh H. Injuries to neck structures in deaths due to constriction of neck, with a special reference to hanging. J Forensic Leg Med 2008;15(5):298-305.

6. Ingale D, Hiremath R, Mugadlimath A, Bagali MA, Manjunath $\mathrm{KH}$, Thirunavukkarasu. structural damage in the neck structures due to hanging. Int J Med Pharm Sci 2013;04(02):15

7. Hussain Z, Shah MM, Afridi HK, Arif M. homicidal deaths by firearms in peshawar: an autopsy study. J Ayub Med Coll Abbottabad 2006;18(1).

8. Sharma BR, Harish D, Singh VP, Singh P. ligature mark on neck: how informative. JIAFM 2005:27(1):10-15.

9. Sadikhusen G. Momin, Mangal HM, Kyada HC, Vijapura MT, Bhuva SD. Pattern of Ligature Mark in Cases of Compressed Neck in Rajkot Region: A Prospective Study. J Indian Acad Forensic Med 2012;34(1):40-43.
10. Jayaprakash S, Sreekumari K. Pattern of injuries to Neck structures in Hanging-An Autopsy Study. Am J Forensic Med Pathol 2012:23.

11. Spitz DJ, Prator PC, Stratton JE, Labiste L, Augenstein JS, Mackinnon J et al. Neck Injuries Caused by Automatic Twopoint seat belts: An Analysis of Four Cases. J Forensic Sci 2005;50(1):1-5

12. Sanjay Gupta. Mysteries of Decapitation Deaths. J Forensic Med Toxicol 2010;27(2);61-2.

13. Kumral B, Büyük Y, Gündoğmuş ÜN, Şahin E, Şahin MF. Medico-legal evaluation of deaths due to decapitation. Rom J Leg Med 2012;(20):251-4.

14. Meshram AH, Nanandkar SD. Concealed Homicide. $J$ Forensic Med Sci Law 2012;21(2).

15. Maselli E, Dell'Erba A, Lobifaro A, Tattoli L, Solarino B. Dismemberment by a tamping machine: An unusual case of work-related accidental decapitation. Rom J Leg Med 2014;(22):1-4.

16. Ling Li, Smialek, John E. The investigation of Fatal Falls and Jumps from Heights in Maryland (1987-1992). Am J Forensic Med Pathol 1994.

17. Murthy CR V, Harish S and YPG Chandra. The Study of Pattern of Injuries in Fatal Cases of fall from a Height, $A l$ Ameen J Med Sci 2012; 5(1):45-52

18. Turk, Elisabeth E, Tokos, Michael. Pathologic features of fatal falls from height. Am J Forensic Med Pathol 2004;25(3):1949.

19. Shetty BS, Padubidri JR, Bhandarkar AM, Shetty AJ, Shetty M. Atypical Suicidal cut throat injury-- a case report. $J$ Forensic Leg Med 2009;16(8):492-3.

20. Apostolov A, Hristov S, Krastev D, Kalniev M, Krastev N. An autopsy case of suicide with three knives: a forensic and anatomical discussion, Res Rep Forensic Med Sci 2013;3:1-5.

21. Sikary AK, Jhamad AR, Millo J. Punjab Acad Forensic Med Toxicol 2013;13(1):38-40.

22. Smith Srisont, AVM Vichan Peonim, Thamrong Chirachariyavej. An Autopsy Case Report of Suicide by Multiple Self-Cutting and Self-Stabbing over the Chest and Neck. J Med Assoc Thai 2009; 92 (6): 861-4.

23. Parthasarathi Pramanik, Udit Das. Neck Trauma by Bicycle Handlebar in Road Traffic Accident -- A Rare Case Report with Review of Literature. J Forensic Med Toxicol 2011;28(2):29-31

24. Demirci S, Dogan KH, Erkol Z, Gunaydin G. Suicide by Ligature Strangulation. Am Forensic Med Pathol 2009;30(4):369-72.

How to cite this article: Gilani FN, Rajaput A, Goudar ES. A Study of pattern of neck injuries in the victims autopsied at tertiary care medical college and hospital of North Karnataka. Int J Forensic Med Toxicol Sci 2019;4(2):28-33. 